ORIGINAL ARTICLE

\title{
CHADS2 Score as a Predictor of Acute kidney Injury in Diabetic Patient Undergoing Elective Coronary Intervention
}

\author{
Tarek Said Zolfakar, NaderTalaat Kandil, Alaa El-Sayed Salama, Ahmed Mohamed \\ Saad* $^{*}$ \\ ${ }^{1}$ Cardiology Department, Faculty of Medicine, Zagazig University, Zagazig, Egypt
}

\begin{abstract}
*Corresponding Author:
Ahmed Mohamed Saad

Cardiology Department,

Faculty of Medicine,

Zagazig University, Egypt.

dr.ahmedsaad45@gmail.com
\end{abstract}

$\begin{array}{ll}\text { Submit Date } & 2019-05-20 \\ \text { Revise Date } & 2019-06-11 \\ \text { Accept Date } & 2019-06-14\end{array}$
Background: one of major adverse outcome of cardiac catheterization is acute kidney injury (AKI), and is associated with short-term and long-term mortality and morbidity. The pathogenesis of AKI is still not established although it is thought that the mechanism is medullary hypoxia lead to renal tubular dysfunction. Objective: The aim of the study is to assess the efficacy of CHADS2 score in prediction of AKI in diabetic patients after percutaneous coronary intervention (PCI).

Methods: This study was prospective cohort study done on 60 patients have diabetic history divided into two groups according to incidence of AKI. All diabetic patients underwent elective PCI. All patients had the following: complete blood count, renal function, glycosylated hemoglobin (HbA1C), Resting electrocardiography, echocardiography Doppler study. Serum creatinine was assessed before intervention, 48 hours after exposure to contrast media in PCI. Creatinine clearance was assessed also before and 48 hours after the intervention. Results: AKI developed in eight patients $((13.3 \%)$ one patient with CHADS2 score $<3$ and 7 patients have CHADS2 score $>3$. The result showed that CHADS2 score is an independent predictor for incidence of AKI [odds ratio $(\mathrm{OR})=8.111 ; 95 \%$ confidence interval $($ C.I $)=1.096-60.011 ; p=0.04]$. There was a significant increase in AKI incidence with increased CHADS2 score. Conclusions: CHADS2 score is more accurate and sensitive in diagnosis of acute kidney injury after coronary intervention in comparison with old complicated scoring system.

Key words: (acute kidney injury, CHADS2, coronary intervention)

\section{INTRODUCTION}

O ne of major adverse outcome of cardiac catheterization is acute kidney injury(1). The reported incidence of AKI is widely varies in different populations, the ranking of AKI from $7 \%$ to $25 \%$, depending mainly on the presence of risk factors $(2,3)$.
It's associated with increased in-hospital and long-term mortality and morbidity, prolonged hospital stay, and long-term renal dysfunction (1) so, risk stratification is very important to apply the appropriate extent of prophylactic strategy in suspected high-risk populations. 
In general, many models have been proposed to predict the incidence of AKI.

In 2004, Mehran (4) reported a scoring system containing 8 variables, with fair correlation to the risk of AKI. In 2013, Gurm (5) created other model containing 15 variables with better discrimination of AKI incidence than Mehran's score. Although the accuracy of this scoring systems it is limited by their complexity and require various examinations to complete the risk stratification.

CHADS2 score is used for risk stratification of embolic events in patient's complaining atrial fibrillation. The components of The CHADS2 score, such as diabetes, age and heart failure, have also been reported also as risk factors for AKI and adverse cardiac events.

Recently the CHADS2 score helps to identify patients with poor outcome in acute myocardial infarction (6) However, information about the usage of the CHADS2 score in predicting AKI is limited.

We conducted this prospective cohort study to determine the correlation between CHADS2 score and risk of AKI in patients with diabetic disease underwent elective PCI.

The aim of our study was to assess the efficacy of CHADS2 in prediction of AKI in diabetic disease patients with normal serum creatinine after elective coronary intervention.

\section{METHODS}

Written informed consent was obtained from all participants and the study was approved by the research ethical committee of Faculty of Medicine, Zagazig University. The work has been carried out in accordance with The Code of Ethics of the World Medical Association (Declaration of Helsinki) for studies involving humans

Our study was a prospective cohort study carried on cardiology department of Zagazig University during the period from October 2015 to December 2018 included 60 randomly selected patients who were admitted to our coronary care unit for elective coronary intervention divided into two groups:

- No AKI group included 52 patients.
- AKI group included 8 patients.

Inclusion criteria Diabetic patient undergo elective coronary angiography, classified according to incidence of AKI.

Exclusion criteria:

Patients were excluded from the study if one or more of the following criteria were present

- Patients with chronic renal disease.

- Patient with acute myocardial infarction.

- Patient with atrial fibrillation.

- Patients with malignancies.

All patients underwent the following:

1- Complete history taking: Including age, sex, smoking, hypertension, dyslipidemia, diabetes mellitus, chronic kidney disease and other medical conditions.

2- Full clinical examination and cardiac assessment: Heart rate, blood pressure, cardiac auscultation and peripheral Pulsation.

3-Electrocradiogram (ECG): A 12-lead surface ECG was done for each patient on admission for diagnosis of ischemic changes or exclude new changed and STEMI.

4- Doppler - echocardiography: for assessment of LV function by $\mathrm{M}$ - mode, regional wall motion abnormality.

5- Laboratory investigations: complete blood count (CBC) and random blood sugar and kidney function (serum urea, serum creatinine, creatinine clearance) before and after coronary intervention and glycosylated hemoglobin (HbA1C\%).

6- Calculating CHADS2 score: Ages > 75 years (1), HTN (1), DM (1), Heart failure (1), Previous stroke or TIA (2).

\section{7- Percutaneous coronary intervention. Swtatistical Analysis}

Data were analyzed using Statistical Program for Social Science (SPSS) version 23. Quantitative data were expressed as mean \pm standard deviation (SD). Qualitative data were expressed as frequency and percentage.

We use the following tests of significance: Independent-samples t-test, Mann Whitney U test ,Chi-square (X2) test, Fisher Exact test and Wilcoxon Signed-Ranks Test. Receiver 
operating characteristic (ROC) curve analysis was used to identify optimal cut-off values.

Sensitivity, specificity, PPV (positive predictive value), NPV (negative predictive value) was used to plot Receiver Operating Curve (ROC).Statistical significance was assessed at $\mathrm{P}$ values less than 0.05 .

\section{RESULTS}

Demographic data of the studied groups

Regarding the age, in no AKI group the age ranged from 39 to 78 years with mean $60 \pm 10.4$ years, in AKI group the age ranged from 55 to 78 years with mean value $68.3 \pm 9.6$ years.

The main difference between the two groups was statistically non-significant ( $\mathrm{P}=0.055)$.

Regarding gender, no AKI group there were 34 males $(65.4 \%)$ and 18 females (34.6\%), AKI group there were 6 males $(75 \%)$ and 2 females (25\%). There was a non-statistically significant difference between the two groups with (Pvalue $=0.707$ ).

Regarding body weight, no AKI group the body weight range from 64 to 115 with mean $86.8 \pm$ 11.9 in AKI group the body weight range from 75 to 90 with mean $83.3 \pm 6.4$.

There was a non-statistically significant difference between the two groups with ( $\mathrm{P}$ value $=0.416$ ).

Regarding smoking, no AKI group there were $20(38.5 \%)$ smoking patient while in AKI group there were two (25\%) smoking patient.

There was a non-statistically significant difference between the two groups with (Pvalue $=0.698)$. (Table1)

The cardiovascular risk factors (CHADS2 score) in each group

Regarding hypertension, no AKI group there were 32 patients hypertensive $(61.5 \%)$ while in AKI group there were 8 patients hypertensive $(100 \%)$.

There was a statistically significant difference between the two groups with $(\mathrm{P}-\mathrm{value}=0.043)$.

Regarding diabetes mellitus, no AKI group there were 52 patients diabetic $(100 \%)$ while AKI group there were 8 patients diabetic $(100 \%)$
There was a non-statistically significant difference between the two groups with ( $\mathrm{P}$ value $=1.00$ ).

Regarding congestive heart failure, no AKI group there were 11 patients with CHF $(21.2 \%)$ while in AKI group there were 2 patients with CHF (25\%).

There was a statistically non-significant difference between the two groups with ( $\mathrm{P}$ value $=1.00$ ).

Regarding history of stroke and TIA, no AKI group there were one patient with history of stroke $(1.9 \%)$ while in AKI group there were 5 patients with history of stroke $(62.5 \%)$

There was a statistically significant difference between the two groups with (P-value $<0.001)$.

Regarding patient age > 75 years, no AKI group there were 8 patients older than 75 years $(15.4 \%)$ while in AKI group there were four patients older than 75 years $(50 \%)$.

There was a statistically significant difference between the two groups with $(\mathrm{P}$-value $=0.043)$. (Table2)

ECG findings of the studied groups

Regarding ECG, in no AKI group there were 5 patients $(9.6 \%)$ had no ECG changes, 26 patients $(50 \%)$ had anterior wall ischemia, 8 patients $(15.4 \%)$ had lateral wall ischemia and 13 patients $(25 \%)$ had inferior wall ischemia.

While in AKI group there were 0 patients $(0 \%)$ had no ECG changes, 2 patients (25\%) had anterior wall ischemia, 1 patient $(12.5 \%)$ had lateral wall ischemia and 5 patients $(62.5 \%)$ had inferior wall ischemia. (Table3)

Abdominal sonographic and echocardiographic data findings of the groups

Regarding Abdominal U/S, in no AKI group there were 43 patients $(82.7 \%)$ had normal U/s while 9 patients $(17.3 \%$ ) had Nephropathy (I) while in AKI group there were 6 patients $(75 \%)$ had normal U/s while 2 patients (25\%) had Nephropathy (I).

There was a non-statistically significant difference between the two groups with (Pvalue $=0.631$ ).

Regarding echocardiography, in no AKI group the EF ranged from 35 to $72 \%$ with mean 58.4 
\pm 9.4 , in AKI group the EF ranged from 35 to $60 \%$ with mean value $51.4 \pm 8.6$.

The main difference between the two groups was statistically non- significant $(\mathrm{P}=0.141)$

(Table4)

\section{Laboratory findings of the studied groups}

\section{Regarding serum creatinine Before PCI:-}

- In-group I the level of creatinine ranged from 0.65 to $1.5 \mathrm{mg} / \mathrm{dl}$ with mean $1.02 \pm 0.25$.

- In-group II the level of creatinine ranged from 0.7 to $1.3 \mathrm{mg} / \mathrm{dl}$ with mean value $1.01 \pm 0.20$. The main difference between the two groups was statistically non-significant $(\mathrm{P}=0.948)$.

\section{Regarding serum creatinine after PCI:-}

- In-group I the level of creatinine from 0.7 to $1.62 \mathrm{mg} / \mathrm{dl}$ with mean $1.07 \pm 0.27$.

- In-group II the level of creatinine ranged from 1.4 to $3.7 \mathrm{mg} / \mathrm{dl}$ with mean value $2.21 \pm 0.69$.

The main difference between the two groups was statistically highly significant $(\mathrm{P}<0.001)$.

The main difference between creatinine level before and after PCI in no AKI group was statistically highly significant $(\mathrm{p}<0.001)$.

In addition, the main difference between creatinine level before and after PCI in AKI group was statistically highly significant $(\mathrm{p}<0.001)$.

Regarding creatinine clearance Before PCI:-

- In-group I the level of creatinine clearance ranged from 52 to $155 \mathrm{ml} / \mathrm{min}$ with mean 95.4 \pm 31.2 .

- In-group II the level of creatinine clearance ranged from 51 to $154 \mathrm{ml} / \mathrm{min}$ with mean value $87.5 \pm 32.8$.

The main difference between the two groups was statistically non-significant $(\mathrm{P}=0.579)$.

Regarding serum creatinine clearance after PCI:-

- In no AKI group the level of creatinine clearance ranged from 48 to $155 \mathrm{ml} / \mathrm{min}$ with mean $91.8 \pm 31.5$.

- In AKI group, the level of creatinine clearance ranged from 24 to $77 \mathrm{ml} / \mathrm{min}$ with mean value $41.1 \pm 17.3$.

The main difference between the two groups was statistically highly significant $(\mathrm{P}<0.001)$.

The main difference between creatinine clearance before and after PCI in no AKI group was statistically highly significant $(\mathrm{p}<0.001)$.

In addition, the main difference between creatinine clearance before and after PCI in AKI group was statistically significant $(\mathrm{p}=0.012)$.

\section{Regarding HBA1c:-}

- In no AKI group, HBA1c ranged from 6.9 to $9.7 \%$ with mean $7.54 \pm 0.50$.

- In AKI group, HBA1c ranged from 7.8 to $9.2 \%$ with mean value $8.36 \pm 0.52$.

The main difference between the two groups was statistically highly significant $(\mathrm{P}<0.001)$. (Table5)

PCI data of the studied groups

Regarding contrast volume (ml), in no AKI group the volume ranged from 125 to $375 \mathrm{ml}$ with mean $233.2 \pm 64.3$, while in AKI group the volume ranged from 250 to $400 \mathrm{ml}$ with mean value $331.3 \pm 49.6$.

The main difference between the two groups was statistically significant $(\mathrm{P}=0.001)$.

Regarding radiation time ( $\mathrm{min}$ ), in no AKI group the time ranged from 20 to 60 min with mean $31.0 \pm 10.1$, while in AKI group the time ranged from 35 to 65 min with mean value 43.1 \pm 10.3 .

The main difference between the two groups was statistically significant $(\mathrm{P}=0.003)$.

Regarding number of vessels, no AKI group there were 38 patients with one vessel lesion $(73.1 \%)$ and 11 patients with two vessel lesion(21.1\%) and 3 patients with three vessel lesion $(5.8 \%)$.

While in AKI group, there were two patients with one vessel lesion (25\%) and six patients with two-vessel lesion (75\%) and no patient with three-vessel lesion $(0 \%)$.

There was a statistically significant difference between the two groups with $(\mathrm{P}$-value $=0.007)$. (Table6)

Logistic regression analysis for CHADS2 score to AKI

There is an increase of one point in the CHADS2 score is associated with a $573.8 \%$ significant increase the incidence of AKI [odds ratio $(\mathrm{OR})=6.738 ; 95 \%$ confidence interval $($ C.I $=2.027$ - 22.399; $\mathrm{p}=0.002]$. (Table7)

Multiple logistic regression analysis for different 


\section{factors to AKI}

A multivariate logistic regression model was performed to ascertain the effects of CHADS2 score, radiation time, contrast volume and age on the likelihood that participants would have AKI. The result showed that CHADS2 score is an independent predictor for incidence of AKI [odds ratio $(\mathrm{OR})=8.111 ; 95 \%$ confidence interval $(\mathrm{C} . \mathrm{I})=1.096-60.011 ; \mathrm{p}=0.04]$. (Table8)

ROC curve analysis regarding AKI

ROC curve analysis was done to pick up the best cut off value of CHADS2 risk scores and incidence of AKI which revealed CHADS2 risk score more than 3 with sensitivity $62.5 \%$ and specificity $96.2 \%$ Area under the curve 0.895 (P-value <0.001). (Table9) (Figure1)

Table 1. Comparison between the studied groups regarding demographic data.

\begin{tabular}{|c|c|c|c|c|}
\hline Demographic data & No AKI & AKI & \multirow{2}{*}{$\begin{array}{l}\text { Fisher's } \\
\text { Exact } \\
\text { test }\end{array}$} & \multirow[t]{2}{*}{$\begin{array}{l}\text { p-value } \\
\text { (Sig.) }\end{array}$} \\
\hline Count (\%) & $52(86.7 \%)$ & $8(13.3 \%)$ & & \\
\hline \multicolumn{5}{|l|}{ Gender } \\
\hline Male & $34(65.4 \%)$ & $6(75 \%)$ & \multirow[t]{2}{*}{$0.288^{\mathbf{F}}$} & \multirow[t]{2}{*}{$0.707(\mathrm{NS})$} \\
\hline Female & $18(34.6 \%)$ & $2(25 \%)$ & & \\
\hline \multicolumn{5}{|l|}{ Age (years) } \\
\hline Mean \pm SD & $60 \pm 10.4$ & $68.3 \pm 9.6$ & \multirow[t]{2}{*}{$-1.917 \bullet$} & \multirow[t]{2}{*}{$0.055(\mathrm{NS})$} \\
\hline Median (Range) & $60(39-78)$ & $71(55-78)$ & & \\
\hline \multicolumn{5}{|l|}{ Weight (kg) } \\
\hline Mean \pm SD & $86.8 \pm 11.9$ & $83.3 \pm 6.4$ & \multirow[t]{2}{*}{$0.819 *$} & \multirow[t]{2}{*}{0.416 (NS) } \\
\hline Median (Range) & $90(64-115)$ & $83.5(75-90)$ & & \\
\hline \multicolumn{5}{|l|}{ Smoking } \\
\hline & $20(38.5 \%)$ & $2(25 \%)$ & $0.541^{\mathbf{F}}$ & $0.698(\mathrm{NS})$ \\
\hline $\begin{array}{l}\text { * Independent samp } \\
\text { - Mann Whitney U } \\
\text { F Fisher's Exact test }\end{array}$ & $\begin{array}{l}\text { dent's t-test. } \\
\text { Chi-square tes }\end{array}$ & & & \\
\hline
\end{tabular}


Table 2. Comparison between the patients with AKI and patients without AKI regarding demographic data.

\begin{tabular}{|c|c|c|c|c|}
\hline $\begin{array}{l}\text { Demographic } \\
\text { data }\end{array}$ & No AKI & AKI & \multirow{2}{*}{$\begin{array}{c}\text { Fisher's } \\
\text { Exact } \\
\text { test }\end{array}$} & \multirow[t]{2}{*}{$\begin{array}{l}\text { p-value } \\
\text { (Sig.) }\end{array}$} \\
\hline Count $(\%)$ & $52(86.7 \%)$ & $8(13.3 \%)$ & & \\
\hline \multicolumn{5}{|l|}{ Dyslipidemia } \\
\hline & $42(80.8 \%)$ & $7(87.5 \%)$ & $0.210^{\mathbf{F}}$ & $1.00(\mathrm{NS})$ \\
\hline \multicolumn{5}{|l|}{ CHF } \\
\hline & $11(21.2 \%)$ & $2(25 \%)$ & $0.06^{\mathbf{F}}$ & $1.00(\mathrm{NS})$ \\
\hline \multicolumn{5}{|l|}{ HTN } \\
\hline & $32(61.5 \%)$ & $8(100 \%)$ & $4.615^{\mathbf{F}}$ & $0.043(\mathrm{~S})$ \\
\hline \multicolumn{5}{|l|}{ Age $\geq 75$ years } \\
\hline & $8(15.4 \%)$ & $4(50 \%)$ & $5.192^{\mathbf{F}}$ & $0.043(\mathrm{~S})$ \\
\hline \multicolumn{5}{|l|}{ DM } \\
\hline & $52(100 \%)$ & $8(100 \%)$ & $<0.001 \ddagger$ & $1.00(\mathrm{NS})$ \\
\hline \multicolumn{5}{|l|}{ History of stroke } \\
\hline & $1(1.9 \%)$ & $5(62.5 \%)$ & $28.27^{\mathbf{F}}$ & $<0.001(\mathrm{HS})$ \\
\hline \multicolumn{5}{|l|}{$\mathrm{CHADS}_{2}$ score } \\
\hline Mean \pm SD & $2.02 \pm 0.83$ & $4.00 \pm 1.31$ & \multirow[t]{2}{*}{$-3.755 \bullet$} & \multirow[t]{2}{*}{$<0.001$ (HS) } \\
\hline Median (Range) & $2(1-4)$ & $4(2-6)$ & & \\
\hline
\end{tabular}

$\mathrm{p}<0.05$ is significant. Sig.: significance.

Table 3 Comparison between the patients with AKI and patients without AKI regarding ECG.

\begin{tabular}{|l|c|c|c|c|}
\hline ECG & No AKI & AKI & $\begin{array}{c}\text { Fisher's } \\
\text { Exact } \\
\text { test }\end{array}$ & $\begin{array}{c}\text { p-value } \\
\text { (Sig.) }\end{array}$ \\
\hline Count $(\%)$ & $52(86.7 \%)$ & $8(13.3 \%)$ & \\
\hline Normal & $5(9.6 \%)$ & $0(0 \%)$ & $4.986 \ddagger$ & $0.173(\mathrm{NS})$ \\
\hline Anterior changes & $26(50 \%)$ & $2(25 \%)$ & \\
\hline Inferior changes & $13(25 \%)$ & $5(62.5 \%)$ & \\
\hline Lateral changes & $8(15.4 \%)$ & $1(12.5 \%)$ & \\
\hline
\end{tabular}

$\mathrm{p}<0.05$ is significant. Sig.: significance. 
Table 4. Comparison between the patients with AKI and patients without AKI regarding abdominal sonographic and echocardiographic data.

\begin{tabular}{|l|c|c|c|c|}
\hline U/S and echo & No AKI & AKI & $\begin{array}{c}\text { Fisher's } \\
\text { Exact } \\
\text { test }\end{array}$ & $\begin{array}{c}\text { p-value } \\
\text { (Sig.) }\end{array}$ \\
\hline Count (\%) & $52(86.7 \%)$ & $8(13.3 \%)$ & \\
\hline Abdominal U/S & $43(82.7 \%)$ & $6(75 \%)$ & $0.274^{\mathbf{F}}$ & 0.631 (NS) \\
\hline Normal & $9(17.3 \%)$ & $2(25 \%)$ & \\
\hline Nephropathy (I) & $55.4 \pm 9.4$ & $51.4 \pm 8.6$ & $1.474 \cdot$ & $0.141(\mathrm{NS})$ \\
\hline EF (\%) & $57.5(35-72)$ & $53.5(35-60)$ & & \\
\hline Mean \pm SD & Median (Range) & & \\
\hline
\end{tabular}

$\mathrm{p}<0.05$ is significant. Sig.: significance.

Table 5. Comparison between the patients with AKI and patients without AKI regarding the laboratory data.

\begin{tabular}{|c|c|c|c|c|}
\hline Laboratory data & No AKI & AKI & \multirow{2}{*}{$\begin{array}{c}\text { Fisher's } \\
\text { Exact } \\
\text { test }\end{array}$} & \multirow{2}{*}{$\begin{array}{l}\text { p-value } \\
\text { (Sig.) }\end{array}$} \\
\hline Count (\%) & $52(86.7 \%)$ & $8(13.3 \%)$ & & \\
\hline \multicolumn{5}{|c|}{ Serum creatinine (mg/dl) } \\
\hline \multicolumn{5}{|l|}{ Before PCI } \\
\hline Mean \pm SD & $1.02 \pm 0.25$ & $1.01 \pm 0.20$ & \multirow[t]{2}{*}{$0.066 \bullet$} & \multirow[t]{2}{*}{$0.948(\mathrm{NS})$} \\
\hline Median (Range) & $1.0(0.65-1.5)$ & $0.95(0.7-1.3)$ & & \\
\hline \multicolumn{5}{|l|}{ After PCI } \\
\hline Mean \pm SD & $1.07 \pm 0.27$ & $2.21 \pm 0.69$ & \multirow{2}{*}{$-4.369 \bullet$} & \multirow[t]{2}{*}{$<0.001(\mathrm{HS})$} \\
\hline Median (Range) & $1.05(0.7-1.62)$ & $2.15(1.4-3.7)$ & & \\
\hline Test & $-4.747^{\#}$ & $-2.527^{\#}$ & & \\
\hline p-value (Sig.) & $<0.001(\mathrm{HS})$ & $0.012(\mathrm{~S})$ & & \\
\hline \multicolumn{5}{|c|}{ Creatinine clearance $(\mathrm{mL} / \mathrm{min})$} \\
\hline \multicolumn{5}{|l|}{ Before PCI } \\
\hline Mean \pm SD & $95.4 \pm 31.2$ & $87.5 \pm 32.8$ & \multirow[t]{2}{*}{$0.555 \bullet$} & \multirow[t]{2}{*}{$0.579(\mathrm{NS})$} \\
\hline Median (Range) & $84.5(52-155)$ & $86.5(51-154)$ & & \\
\hline \multicolumn{5}{|l|}{ After PCI } \\
\hline Mean \pm SD & $91.8 \pm 31.5$ & $41.1 \pm 17.3$ & \multirow[t]{2}{*}{$3.959 \bullet$} & \multirow[t]{2}{*}{$<0.001(\mathrm{HS})$} \\
\hline Median (Range) & $81(48-155)$ & $37.5(24-77)$ & & \\
\hline Test & $4.675^{\#}$ & $2.521 *$ & & \\
\hline p-value (Sig.) & $<0.001(\mathrm{HS})$ & $0.012(\mathrm{~S})$ & & \\
\hline \multicolumn{5}{|c|}{ HbA1c (\%) } \\
\hline Mean \pm SD & $7.54 \pm 0.50$ & $8.36 \pm 0.52$ & \multirow[t]{2}{*}{$-3.775 \bullet$} & \multirow[t]{2}{*}{$<0.001$ (HS) } \\
\hline Median (Range) & $7.4(6.9-9.7)$ & $8.2(7.8-9.2)$ & & \\
\hline
\end{tabular}

$\mathrm{p}<0.05$ is significant. Sig.: significance. 
Table 6. Comparison between the patients with AKI and patients without AKI regarding PCI data.

\begin{tabular}{|c|c|c|c|c|}
\hline PCI data & No AKI & AKI & \multirow[t]{2}{*}{$\begin{array}{l}\text { Fisher's } \\
\text { Exact test }\end{array}$} & \multirow[t]{2}{*}{$\begin{array}{l}\text { p-value } \\
\text { (Sig.) }\end{array}$} \\
\hline Count (\%) & $52(86.7 \%)$ & $8(13.3 \%)$ & & \\
\hline \multicolumn{5}{|l|}{$\begin{array}{l}\text { Contrast volume } \\
(\mathrm{mL})\end{array}$} \\
\hline Mean \pm SD & $233.2 \pm 64.3$ & $331.3 \pm 49.6$ & \multirow[t]{2}{*}{$3.448 \bullet$} & \multirow[t]{2}{*}{$0.001(\mathrm{~S})$} \\
\hline Median (Range) & $225(125-375)$ & $\begin{array}{c}337.5(250- \\
400)\end{array}$ & & \\
\hline \multicolumn{5}{|l|}{$\begin{array}{l}\text { Radiation time } \\
\text { (min) }\end{array}$} \\
\hline Mean \pm SD & $31.0 \pm 10.1$ & $43.1 \pm 10.3$ & \multirow[t]{2}{*}{$-2.972 \bullet$} & \multirow[t]{2}{*}{$0.003(\mathrm{~S})$} \\
\hline Median (Range) & $30(20-60)$ & $40(35-65)$ & & \\
\hline \multicolumn{5}{|l|}{ N. of vessels } \\
\hline One vessel & $38(73.1 \%)$ & $2(25 \%)$ & \multirow[t]{3}{*}{$9.960 \div$} & \multirow[t]{3}{*}{$0.007(\mathrm{~S})$} \\
\hline Two vessels & $11(21.1 \%)$ & $6(75 \%)$ & & \\
\hline Three vessels & $3(5.8 \%)$ & $0(0 \%)$ & & \\
\hline
\end{tabular}

$\mathrm{p}<0.05$ is significant. Sig.: significance.

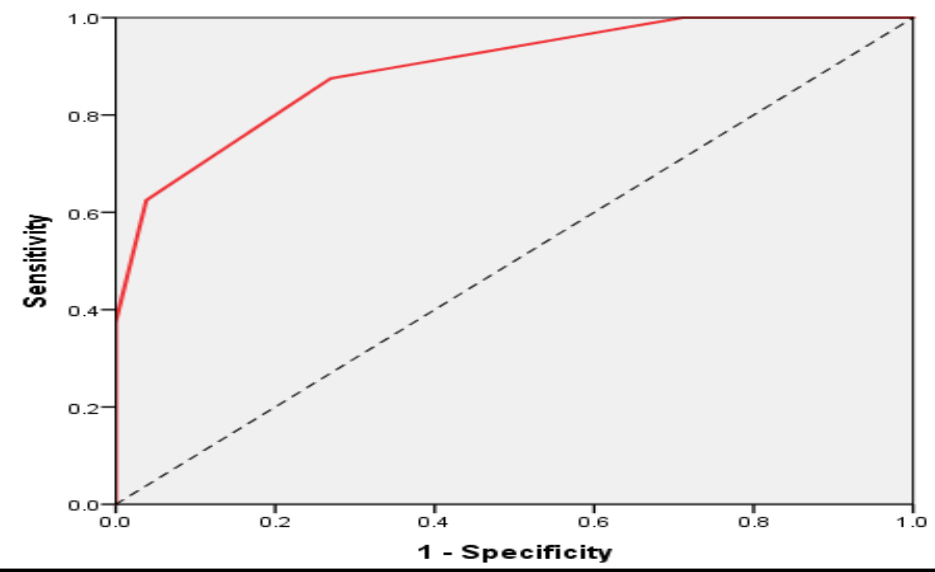

Figure 1. ROC curve analysis

\section{DISCUSSION}

The progress of imaging methods and interventional procedures require administration of contrast media in cardiac modalities(e.g., coronary angiography and PCI) and emerging cardiac modalities (e.g., CT coronary angiography and trans catheter aortic valve implantation (TAVI)) has increased the number of patients exposed to contrast media and increase the risk of $\mathrm{AKI}(7)$.

AKI is associated with a marked increase in mortality and morbidity rates (8).

Despite technological advances, AKI incidence remains responsible for about third of all hospital-acquired acute kidney dysfunction (9), and affects between $1 \%$ and $2 \%$ of the general population and up to $50 \%$ 
of high-risk groups following both coronary angiography and percutaneous coronary intervention (10).

Identification of patients at increased risk for AKI is challenging. Although the mechanisms of AKI is not fully understood, researchers concluded that AKI is caused by renal vasoconstriction, endothelium cell damage, endothelial dysfunction, followed by medullary hypoxia and renal tubular injury (11).

Advanced age, diabetes mellitus, female gender, renal dysfunction and CHF, (12) are already well-known risk factors for AKI.

Even high central pulse pressure and hypertension have been reported to be linked to AKI development (13).

The components of the CHA2DS2-VASC and CHADS2 score include similar risk factors for AKI (10).

The CHADS2 score was initially developed for stratification of stroke risk in patients with AF is also a convenient scoring system for detecting the complexity of comorbidities in patients with known cardiovascular diseases (14).

There is limited data about the value of the CHADS2 score in the incidence of AKI after patients undergo PCI, but the components of the CHADS2 score are risk factors for development of AKI (4).

The aim of our study was to assess whether the CHADS2 score provide potentially valuable prognostic information's on incidence of AKI.

Our study was conducted on 60 diabetic patients with normal serum creatinine undergoing elective PCI divided into two groups according to incidence of AKI.

Serum creatinine was assessed before and after (within 48 hours) contrast media exposure in the elective PCI.

\section{Demographic data:}

In our study conducted on 60 patients with mean age $61.1 \pm 10.6$ years and mean body weight $86.3 \pm 11.3 \mathrm{~kg}$ divided into:-

- No AKI group the mean age was $60 \pm$ 10.4years.

- AKI group the mean age was $68.3 \pm$ 9.6years.

There was no statistically significant difference between both groups $(\mathrm{p}=0.055)$. This was in disagreement with Puurunen et al.,(15) who found that there was a highly statistically significant difference regarding Age $(\mathrm{p}<0.001)$.

According to sex our study included 60 patients 20 (33.3\%) female and 40 (66.6\%) male divided into:

- Group I 18 female (34.6\%) and 34 male (65.4\%).

- Group II 2 female (25\%) and 6 male (75\%). There was no significant difference between both groups $(p=0.707)$ regarding sex. This was in disagreement with James et al.,(16) which examine the association between AKI following coronary angiography, they found that males were $69.9 \%$ in the low risk CHADS2 group compared to $57.7 \%$ in high risk group $(\mathrm{p}=0.007)$.

\section{Clinical data and risk factors:}

In our study, there was a statistical significant difference regarding hypertension (32 patients in group I and 8 patients in group II), history of stroke (5 patients in group II with one patient in group I) and Congestive heart failure (11 patients in group I and 2 patients in group II) between the two groups which was concordant with Chou et al., (17), in which 539 patient underwent coronary angiography and intervention divided according to CHADS2 score, While there was no statistically significant difference concerning diabetes between both groups and this was against the result of Chou et al., (17).

Regarding to serum creatinine:

- Before PCI: 
It was $1.02 \pm 0.25 \mathrm{mg} / \mathrm{dl}$ Group I while in Group II it was $1.01 \pm 0.20 \mathrm{mg} / \mathrm{dl}$ with no statistically significant difference between both groups which was concordant with (shukla AN et al, (18) in which , 253 patients underwent coronary angiography and/or percutaneous coronary intervention and stated that the mean serum creatinine rise was non-significant.

- 48 hours after PCI:

It was $1.07 \pm 0.27 \mathrm{mg} / \mathrm{dl}$ in group I and $2.21 \pm 0.69 \mathrm{mg} / \mathrm{dl}$ in group II with statistically significant difference between both groups which was concordant with Chou et al (17).

In both group I and group II there was highly statistical significant difference between levels of serum creatinine after PCI.

Although all patients were diabetic but there was a statistical significant difference between both groups regarding $\mathrm{HbA} 1 \mathrm{C}$.

There was no statistically significant difference between both groups regarding dyslipidemia and smoking which was concordant with Ashalatha et al, (19).

There was statistically significant difference between both groups regarding the mean volume of contrast media, radiation time and angiographic findings.

In our study, increased mean volume of CM in PCI was associated with higher incidence of AKI which was concordant with the study of Marenzi et al., (20) which assessed the association between the contrast volume and the incidence of AKI in 561 patients with STEMI underwent Primary PCI.

The incidence of AKI was $13.3 \%$ (8 patients) which was in agreement with Merenzi et al., (7) in which 208 patients presented with acute myocardial infraction underwent Primary PCI the incidence of AKI was 19\%, and disconcordant with Shacham et al.,(21) in which the incidence of AKI was $6.2 \%$.
In our study, CHADS2 score $>3$ is a predictor for the incidence of AKI with sensitivity $62.5 \%$, specificity of $96.2 \%$ and accuracy of $91.7 \%$.

\section{CONCLUSION}

CHADS2 score is highly sensitive in diagnosis of acute kidney injury after coronary intervention in diabetic patients rather than old scoring system.

\section{Limitations of the study}

1-Relatively small sample size of this study.

2-The results were obtained from only two centers.

\section{RECOMMENDATION}

This study recommends using CHADS2 as a diagnostic tool for acute kidney injury in patients undergoing elective PCI.

\section{Declaration of interest}

The authors report no conflicts of interest. The authors alone are responsible for the content and writing of the paper.

Funding information: None declared

\section{REFERENCES}

1. Ting, H.H., Tahirkheli, N.K., Berger, P.B., McCarthy, J.T., Timimi, F.K., Mathew, V., Rihal, C.S., Hasdai, D. and Holmes, J.D., 2001. Evaluation of longterm survival after successful percutaneous coronary intervention among patients with chronic renal failure. The American journal of cardiology, 87(5), pp.630-3.

2. Rudnick, M.R., Goldfarb, S., Wexler, L., Ludbrook, P.A., Murphy, M.J., Halpern, E.F., Hill, J.A., Winniford, M., Cohen, M.B. and VanFossen, D.B., 1995. Nephrotoxicity of ionic and nonionic contrast media in 1196 patients: a randomized trial. Kidney international, 47(1), pp.254-261.

3. Brar, S.S., Shen, A.Y.J., Jorgensen, M.B., Kotlewski, A., Aharonian, V.J., Desai, N., Ree, M., Shah, A.I. and Burchette, R.J., 2008. Sodium bicarbonate vs sodium chloride for the prevention of contrast medium-induced nephropathy in 
patients undergoing coronary angiography: a randomized trial. Jama, 300(9), pp.1038-1046.

4. Mehran, R., Aymong, E.D., Nikolsky, E., Lasic, Z., Iakovou, I., Fahy, M., Mintz, G.S., Lansky, A.J., Moses, J.W., Stone, G.W. and Leon, M.B., 2004. A simple risk score for prediction of contrastinduced nephropathy after percutaneous coronary intervention: development and initial validation. Journal of the American College of Cardiology, 44(7), pp.13931399.

5. Gurm, H.S., Seth, M., Kooiman, J. and Share, D., 2013. A novel tool for reliable and accurate prediction of renal complications in patients undergoing percutaneous coronary intervention. Journal of the American College of Cardiology, 61(22), pp.22422248.

6. Huang, S.S., Chen, Y.H., Chan, W.L., Huang, P.H., Chen, J.W. and Lin, S.J., 2014. Usefulness of the CHADS2 score for prognostic stratification of patients with acute myocardial infarction. The American journal of cardiology, 114(9), pp.1309-1314.

7. Marenzi, G., Lauri, G., Assanelli, E., Campodonico, J., De Metrio, M., Marana, I., Grazi, M., Veglia, F. and Bartorelli, A.L., 2004. Contrast-induced nephropathy in patients undergoing primary angioplasty for acute myocardial infarction. Journal of the American College of Cardiology, 44(9), pp.17801785.

8. McCullough, P.A., 2008. Contrastinduced acute kidney injury. Journal of the American College of Cardiology, 51(15), pp.1419-1428.

9. Nash, K., Hafeez, A. and Hou, S., 2002. Hospital-acquired renal insufficiency. American Journal of Kidney Diseases, 39(5), pp.930-936.
10. Mehran, R. and Nikolsky, E., 2006. Contrast-induced nephropathy: definition, epidemiology, and patients at risk. Kidney International, 69, pp.S11S15.

11. Caiazza, A., Russo, L., Sabbatini, M. and Russo, D., 2014. Hemodynamic and tubular changes induced by contrast media. BioMed research international, 2014.

12. Kurtul, A., Murat, S.N., Yarlioglues, M., Duran, M., Ocek, A.H., Celik, I.E., Kilic, A., Koseoglu, C., Oksuz, F. and Baris, V.O., 2015. Procalcitonin as an early predictor of contrast-induced acute kidney injury in patients with acute coronary syndromes who underwent percutaneous coronary intervention. Angiology, 66(10), pp.957963.

13. Huang, S.S., Huang, P.H., Leu, H.B., Wu, T.C., Lin, S.J. and Chen, J.W., 2013. Association of central pulse pressure with contrast-induced nephropathy and clinical outcomes in patients undergoing coronary intervention. Journal hypertension, 31(11), pp.2187-2194.

14. Gage, B.F., Waterman, A.D., Shannon, W., Boechler, M., Rich, M.W. and Radford, M.J., 2001. Validation of clinical classification schemes for predicting stroke: results from the National Registry of Atrial Fibrillation. Jama, 285(22), pp.28642870.

15.Puurunen, M.K., Kiviniemi, T., Schlitt, A., Rubboli, A., Dietrich, B., Karjalainen, P., Nyman, K., Niemelä, M., Lip, G.Y. and Airaksinen, K.J., 2014. CHADS2, CHA2DS2-VASc and HAS-BLED as predictors of outcome in patients with atrial fibrillation undergoing percutaneous coronary intervention. Thrombosis research, 133(4), pp.560-566. 
16. James, M.T., Ghali, W.A., Tonelli, M., Faris, P., Knudtson, M.L., Pannu, N., Klarenbach, S.W., Manns, B.J. and Hemmelgarn, B.R., 2010. Acute kidney injury following coronary angiography is associated with a long-term decline in kidney function. Kidney international, 78(8), pp.803-809.

17. Chou, R.H., Huang, P.H., Hsu, C.Y., Leu, H.B., Huang, S.S., Huang, C.C., Chen, J.W. and Lin, S.J., 2016. CHADS2 score predicts risk of contrast-induced nephropathy in stable coronary artery disease patients undergoing percutaneous coronary interventions. Journal of the Formosan Medical Association, 115(7), pp.501-509.

18. Shukla, A.N., Juneja, M., Patel, H., Shah, K.H., Konat, A., Thakkar, B.M., Madan, T. and Prajapati, J., 2017. Diagnostic accuracy of serum cystatin $\mathrm{C}$ for early recognition of contrast induced nephropathy in Western Indians undergoing cardiac catheterization. Indian Heart Journal, 69(3), pp.311-315.
19. Ashalatha, V.L., Bitla, A.R., Kumar, V.S., Rajasekhar, D., Suchitra, M.M., Lakshmi, A.Y. and Rao, P.V.L.N.S., 2017. Biomarker response to contrast administration in diabetic and nondiabetic patients following coronary angiography. Indian journal of nephrology, 27(1), p.20.

20. Marenzi, G., Assanelli, E., Campodonico, J., Lauri, G., Marana, I., De Metrio, M., Moltrasio, M., Grazi, M., Rubino, M., Veglia, F. and Fabbiocchi, F., 2009. Contrast volume during primary percutaneous coronary intervention and subsequent contrast-induced nephropathy and mortality. Annals of internal mediAKIe, 150(3), pp.170-177.

21. Shacham, Y., Gal-Oz, A., Ben-Shoshan, J., Keren, G. and Arbel, Y., 2016. Prognostic implications of acute renal impairment among ST elevation myocardial infarction patients with preserved left ventricular function. Cardiorenal mediAKIe, 6(2), pp.143-149.

To Cite This Article: Tarek SZ., Nader TK, Alaa ES, Ahmed MS. CHADS2 Score as a Predictor of Acute kidney Injury in Diabetic Patient Undergoing Elective Coronary Intervention. ZUMJ 2020;26(1);7586.DOi: 10.21608/zumj.2019.12188.1213 